\title{
ECONOMIA Y FRANQUISMO: \\ A PROPOSITO DE UNA BIOGRAFIA *
}

\author{
PEDRO TEDDE DE LORCA \\ Universidad de Málaga
}

Juan Pablo Fusi es un historiador de temas políticos contemporáneos que se distingue tanto por el interés general de los problemas que aborda -incluso puede hablarse, en este sentido, de actualidad de dichos problemascomo por el esfuerzo que evidencia en analizarlos con objetividad ideológica y rigor crítico. Acerca de la objetividad ideológica de los historiadores, es sabido que surgen muchas dudas sobre su real existencia, y son conocidas las posiciones pesimistas -a propósito de la ecuanimidad - basadas en la inexorable influencia que sobre los resultados científicos tendrían la pertenencia a una clase social, los prejuicios religiosos o políticos e incluso las características psicosomáticas del historiador. En el caso de Juan Pablo Fusi, es obligado reconocer su permanente cuidado por no involucrar sus particulares preferencias en su crítica de personajes y situaciones históricos; cuando trata, como en este caso, de un general que ejerció un prolongado poder político autoritario, el lector de Fusi sabe que el personaje estudiado se alejó de los comportamientos habituales de las democracias contemporáneas -modelo político explícitamente preferido por el autor-, pero sin que ello convierta automáticamente a Franco, por antipatía, en un pésimo militar o en un nefasto gestor económico y social.

Juan Pablo Fusi había publicado hasta ahora estudios sobre política obrera en la Restauración, sobre la génesis histórica de la realidad presente del País Vasco, sobre la Segunda República y la transición desde el franquismo al actual sistema democrático, en colaboración, en este último caso, con su maestro Raymond Carr. El libro que aquí se comenta viene, por tanto, a representar un capítulo que hasta ahora faltaba en la consideración por Fusi de los últimos cien años de vida española. $\mathrm{Y}$ si bien no se trata, como advierte el autor al comienzo del libro, de una investigación biográfica acerca de Franco a partir de datos nuevos, constituye un ensayo de interpretación global de su persona y de su obra, desde sus experiencias africanas hasta su muerte, desde

* Juan Pablo Fusi, Franco. Autoritarismo y poder personal (Prólogo de Edward Malefakis), Ed. El País, Madrid, 1985, 283 pp. 
sus realizaciones militares a sus prolongadas y mudables experiencias en política económica y social y en relaciones internacionales.

$\mathrm{El}$ autor define a este libro como ensayo biográfico, es decir, como un intento de interpretación general e histórica de un personaje sin la aportación de nuevas pruebas documentales. Pero la extensa investigación bibliográfica que este ensayo incorpora, así como la ambiciosa revisión de un largo período histórico y de los diferentes aspectos de la gestión de Franco, hacen de la obra un valioso instrumento para conocer, en síntesis de menos de trescientas páginas, los capítulos fundamentales de la vida española a lo largo de casi medio siglo. En el sentido literal de la palabra, este ensayo puede ser -y deseamos que lo sea- la versión germinal de una obra más amplia y compleja, cuyas afirmaciones fundamentales hubieran sido ya adelantadas como hipótesis interpretativas del personaje central del libro.

¿Cuáles serían estas hipótesis? Para Juan Pablo Fusi, el general Franco fue ante todo un militar nacionalista, de tempranas y declaradas ideas antiliberales, heredero de las ideas regeneracionistas que él articulaba en torno a un tradicionalismo ideológico sin fisuras, prestigioso militar - aunque anticuado estratega, como lo demostraría en Marruecos y en la guerra civil-, autoritario de opiniones indiscutidas, enemigo radical del debate partidista y del juego parlamentario, constante en sus convicciones y en sus hostilidades, prudente en sus movimientos y decisiones, ignorante de cuestiones económicas, poseedor de una indudable habilidad política, sagaz táctico en el campo de batalla y en las relaciones exteriores, y agraciado por una buena suerte que le permitiría prolongar su mandato con resultados evidentes a lo largo de cuarenta años.

Muchas son las cuestiones de importancia planteadas, y todavía en abierto y vivo debate, acerca del protagonismo de Franco en la vida española. Por ejemplo, su tan alabada capacidad de maniobra, ante Hitler, para mantener a España al margen de la guerra mundial. Es reciente, por ejemplo, la opinión de algunos historiadores según la cual la neutralidad española fue posible gracias no al interés de Franco en este sentido, sino al de los dictadores del Eje. Fusi, por su parte, describe detenidamente este capítulo de la historia contemporánea y explica con argumentos plausibles el desenvolvimiento de los hechos entre 1939 y 1946, mostrando las vacilaciones del Gobierno español ante la entrada en el conflicto y el recurso de Franco a la dilación y la desmesurada petición como fórmulas disuasorias.

Otra cuestión de indudable trascendencia histórica y de interés polémico -que afecta más de lleno a los problemas de que habitualmente trata la REvista DE Historia ECONómica - es la que se refiere al éxito y a las consecuencias de la política económica seguida por Franco, especialmente entre 1955 y 1975 . Todas las opiniones parecen coincidir en los errores acumulados en 
la etapa anterior, de la autarquía, e incluso aquellas más favorables en su juicio general del franquismo reconocen que significó una experiencia insostenible, con unos resultados claramente negativos para la evolución de la productividad de la economía española, para la asignación de los recursos y los bienes intermedios y finales y para el bienestar, en términos de consumo, de la mayoría de los españoles, en especial de las capas medias e inferiores de los centros urbanos. Ni los efectos devastadores de la guerra civil, ni el aislamiento político y económico de España tras el fin de la guerra mundial, ni las adversidades climáticas de la agricultura, pueden justificar la política económica elegida o el estancamiento resultante a lo largo de un decenio. Como señala Fusi, la política autárquica no fue tanto un obligado recurso del franquismo ante las circunstancias de 1940-1950 (escasez de divisas, necesidad de reconstruir la infraestructura, malas cosechas, falta de energía) como la plasmación de un proyecto ideológico, de un nuevo orden económico y social basado en la ausencia de intereses partidistas y de clase, en la dirección central enérgica de la política económica, en el nacionalismo y, como consecuencia, en la desconfianza hacia las relaciones económicas internacionales abiertas y libres. Juan Pablo Fusi, en mi opinión acertadamente, relaciona esta ideología económica con la doctrina primorriverista, que buscaba la modernización y el progreso material de España sobre la triple fórmula, de raíz regeneracionista, del aunamiento de voluntades sociales, del efecto estimulante de las obras públicas y del orden público como atmósfera aseguradora del aumento de productividad. Pedro Schwartz y Manuel Jesús González ya habían advertido el parentesco ideológico de las ideas económicas de Franco con las de Primo de Rivera y de las de éste con las de Lucas Mallada, Macías Picavea y Costa, aunque -como recientemente han señalado Francisco Comín y Pablo Martín Aceña - en el período primorriverista hubo una mayor aproximación a la economía de mercado ortodoxa de la que hubo en la primera etapa del franquismo, como lo prueban los intentos de vuelta al patrón-oro, la estabilidad de los precios en la década de 1920 o la relativa moderación en el incremento del déficit presupuestario. Por su parte, el historiador Javier Tusell ha definido el primitivo plan económico franquista como una traslación de los esquemas ordenadores de la intendencia militar a la economía de una nación. Probablemente, en las ideas económicas de Franco, además de la influencia del patriotismo de raíz militar, más proclive a la homogeneidad y a la disciplina en las actuaciones sociales como fórmulas garantes de eficacia a corto plazo, se puede detectar un profundo recelo ante el libre juego de mercado, tanto en el interior de la economía como en las relaciones con el exterior; y puede que este recelo tenga, a su vez, puntos de contacto con la afición de Franco a las interpretaciones conspiratorias de la vida política, que Fusi analiza en el capítulo 4 de su libro. 
En la década de 1940 se delinean algunas de las características intervencionistas de la economía franquista, como la creación del INI -cuyos estatutos lo definían como institución dirigida a conseguir la autarquía económica-, el fuerte control gubernamental de los precios y las producciones agrarias, y la rigidez institucional del sector exterior. El arraigo que estas características han tenido en la reciente historia económica de España se pone de manifiesto al considerar que, en mayor o menor grado, permanecieron vigentes hasta el final del franquismo. $\mathrm{Y}$ algunas de sus derivaciones, como las empresas públicas de dimensiones espectaculares —erigidas en muchos casos sin un suficiente análisis previo de coste-beneficio, o sin una visión a plazo largo de su rentabilidad-, constituyen uno de los problemas más difíciles de resolver para la actual política económica.

A finales de la década de 1940 son observables algunos cambios de importancia en el comportamiento de la economía española; la inversión privada crece sostenidamente desde 1945 a 1955; también lo hace la inversión en vivienda y la formación de capital en la industria, en detrimento de la agricultura, estableciendo la base, como ha señalado Manuel Jesús González, para la conversión, en la década siguiente, de la economía española en una economía industrial. Todo ello con un progresivo crecimiento de los precios de los productos industriales (sobre todo en torno a 1950), que, a su vez, sirvió de estímulo para la inversión preferente en el sector secundario. Las especiales circunstancias del sector exterior -bloqueo internacional, relación real de intercambio desfavorable para España, escasez de medios de pago, fuerte control administrativo del mercado - impidieron la adaptación suave de la industria al proceso de reconstrucción.

En 1955, los datos estadísticos muestran que España, desde unos años atrás, recuperó los niveles de renta per capita inmediatamente anteriores a la guerra civil, y que, además, se había convertido en un país industrializado, si se aceptan para esta definición los criterios tradicionales de Colin Clark: el producto del sector industrial representa un porcentaje de Renta Nacional superior al del sector primario (22,19 frente al 19,48 por 100 , respectivamente) y la población activa en agricultura y pesca supone menos de la mitad -el 46 por 100 - de la población activa total. Pero estas mismas cifras indican la parquedad del progreso conseguido; así, por ejemplo, de los trabajos de Vicente Pérez Moreda sobre población activa se deduce que la proporción de trabajadores en el sector primario, en la España de mediados del siglo xx, era apenas un 13 por 100 más baja que la de Italia a comienzos de siglo, y un 10 por 100 inferior a la de España en 1920. España, en 1955, estaba aún tanteando el umbral de las economías desarrolladas.

Fusi —en el capítulo 5 de su libro- ilustra eficazmente la secuencia histórica experimentada por la economía española en el primer lustro de la dé- 
cada de 1950: retirada de las cartillas de racionamiento, liberalización de los precios y del comercio exterior, mayor flexibilidad a la invèrsión privada, apoyo crediticio a la iniciativa de los particulares, conversión del INI en instrumento público de subsidiariedad, en vez de en sujeto protagonista de la industrialización. Las aperturas de grandes fábricas públicas como Ensidesa o Seat fueron llamativos ejemplos, frente a la opinión pública, de la recuperación, tardía y lenta pero recuperación al fin y al cabo, de la economía española tras la postguerra y de su progresiva transformación.

Fusi coincide con Manuel Jesús González al señalar el año 1951 como un punto de inflexión en la trayectoria económica del régimen de Franco; en esa fecha se produce un cambio de Gobierno -Arburúa se haría cargo de la cartera de Comercio- en que se suavizaría la política intervencionista, y la actitud del exterior, y en especial de Estados Unidos, hacia España se modificó claramente, tanto desde el punto de vista comercial como del de la ayuda económica - 62,9 millones de dólares-, que desembocaría, dos años más tarde. en los tratados de ayuda mutua.

La relación entre España y el exterior fue, según las evidencias disponibles, el antecedente inmediato y principal de la transformación económica y del propio cambio social operado, sobre todo, a partir de 1960 . La situación política internacional en la década de 1950 propiciaba un acercamiento de España a los países occidentales. La propia evolución económica de estos países, con un crecimiento espectacular en esos años, favorecía el incremento de los intercambios de bienes y servicios y de los flujos de capital hacia España. Pero las características del sector exterior de la economía española impidieron, hasta 1959, que esas relaciones fueran suficientemente dinámicas. La escasa propensión a exportar de la economía española, excesivamente protegida y orientada hacia el interior; la complejidad y rigidez de los mecanismos de intercambio y la legislación sobre inversiones extranjeras actuaban como frenos respecto a las posibilidades de importar tecnología y equipo capital, necesarios para la modernización de la economía española y para el aumento de su productividad. A ello, como factor negativo para los intercambios con el exterior, había que unir el proceso inflacionista desatado en la década de 1950 como consecuencia del déficit público, financiado a través del sistema bancario. Por estas razones, los síntimas de progreso económico detectables en los primeros años del decenio de 1950, como el aumento de la inversión industrial, y en buena medida debidos a las exportaciones de productos primarios y a la ayuda americana, acabaron frustrándose a los pocos años.

Fue necesario el plan de estabilización de 1959 para moderar los precios, equilibrar la política monetaria, liberalizar el sector exterior y posibilitar el crecimiento de las exportaciones españolas y las inversiones en nuestro país. Los resultados de este trascendental cambio de la política económica son evi- 
dentes: si entre 1955 y 1960 el Producto Interior Bruto, a precios constantes, creció a una tasa anual del 2,35 por 100 , entre 1960 y 1965 lo hizo a una del 8,25 por 100 , y entre 1965 y 1970 , a una del 7,01 por 100 . Aunque en 1965 la población activa empleada en agricultura y pesca, un 33 por 100 del total, representaba una proporción más alta que en otros países occidentales, había descendido un 13 por 100 respecto a la de 1955. En 1975, la población activa del sector primario había descendido otro 10 por 100 en relación a la de 1965 , y su porcentaje sobre la población activa total era del 23 por 100 . En veinte años, de 1955 a 1975 , el producto del sector primario pasó de representar el 20,5 por 100 del Producto Interior Bruto al 9,7 por 100; el producto industrial, del 31,5 por 100 al 31,8; la construcción, del 6,4 al 7,3 por 100, y los servicios, del 41,5 al 51,2 por 100. En el mismo período, las rentas del trabajo crecieron a un ritmo aproximadamente doble de aquel a que crecieron las rentas del capital. En 1975, las rentas del trabajo suponían el 62,8 por 100 de la Renta Nacional, cuando en 1955 habían supuesto el 46,5 por 100. Con ello no sólo cabe hablar de proceso de revolución industrial o crecimiento económico en el franquismo, sino también de aumento de bienestar para la clase trabajadora y mayor homogeneización social.

Juan Pablo Fusi ilustra esta evolución en el capítulo 6 de su libro, para concluir que los avances en la modernización de la economía española pusieron en evidencia las contradicciones entre dicho proceso y las limitaciones del modelo político que estaba establecido. Fusi señala que los conflictos surgidos en las décadas de 1960 y 1970 no fueron ni generalizados ni coordinados; aún más, hubo reacciones de amplios sectores de la población frente a la disconformidad planteada por determinados grupos. Pero esas contradicciones eran cada vez mayores y particularmente sensibles en el mundo sindical, en el universitario y en el de los nacionalismos vasco y catalán.

El crecimiento económico y la modernización de la sociedad española fueron posible gracias a dos grandes fuerzas: la influencia del exterior y el avance en el conocimiento general de la economía. Y estas dos fuerzas eran completamente ajenas (aún más, contrarias) a la inspiración del modelo político implantado a partir de 1939. La falta de familiaridad del régimen de Franco con las reglas básicas de la economía de mercado —que, a pesar del intervencionismo y los controles, siempre estuvo vigente- se demuestra en múltiples ocasiones. Quizá sea una de las más llamativas la de la famosa subida de salarios decretada por el ministro Girón en 1954; esta subida provocó, debido a su forma de financiación, una inflación que acabó disminuyendo, a los dos años, la participación de los salarios en la renta nacional. La falta de perspectiva económica de los dirigentes españoles antes de 1959 puede ilustrarse de muchas maneras; sirva como muestra un discurso del propio general Franco en Málaga, ya entrada la segunda mitad de la década de 1950 —es decir, cuando estaba esa provincia 
a punto de convertirse en una importantísima zona turística-, en que prometió un proyecto industrializador que convertiría en gris el habitual color azul de su cielo.

La extensión de los conocimientos científicos de la economía en la sociedad española, sobre todo a partir de la Universidad, en combinación con la influencia del exterior, hicieron posible el cambio notorio en la actividad económica a partir de 1959. Este proceso, apasionante en su desarrollo, ha sido relatado con detalle por algunos especialistas, como el citado Manuel Jesús González, Jacinto Ros y sus colaboradores o el equipo que dirigió Angel Viñas en su historia del comercio exterior desde 1931 hasta 1975 . La realidad que salió de ese proceso de cambio confirmó la proximidad de la economía española a las economías occidentales. Incluso en algunos de los rasgos negativos más sobresalientes que observa Juan Pablo Fusi en la adaptación de España al crecimiento económico subsiste esa familiaridad de caracteres. Así, por ejemplo, es imposible, por definición, que una economía deje de ser agraria, para pasar a basarse mayoritariamente en la industria y los servicios, sin que se produzca un trasvase masivo de la población rural a las ciudades. En los casos de industrialización de Alemania o Italia, la intensidad del fenómeno migratorio, hacia el exterior del país, fue mucho más acusado que en el caso de España. La agricultura, cuando se produce la modernización económica, aunque ésta surja propiciada desde otros sectores, como el comercio o la producción de manufacturas, suele liberar recursos con destino a las actividades más dinámicas, ya sea factor trabajo, ya sea ahorro - incluso ahorro forzoso, a través de los impuestos o la inflación- $\_$o ambos. Ello no resta, sin embargo, razón al juicio desfavorable que merecen algunas secuelas del desarrollo español, como las importantes destrucciones del paisaje y medio ambiente o las insuficiencias asistenciales en sanidad o enseñanza que lo acompañaron, o el injusto reparto de la carga tributaria en los decenios de 1950 y 1960 . No obstante, y en este último caso no hay que dejar de matizar algunos aspectos; la distribución de los impuestos favorecía a los perceptores de rentas no salariales, y en la medida en que de ellos procediera la mayor proporción del ahorro nacional, cabe deducir que, en determinadas circunstancias, favorecía la inversión. Es desde el punto de vista de la equidad y de la solidaridad social desde el que cabe criticar la injusticia del sistema tributario español. De hecho, y a pesar del intervencionismo del Estado en la vida económica española -que no desapareció tras el plan de estabilización y liberalización de 1959-, la participación directa del sector público en el proceso de inversión fue siempre por detrás del sector privado. De los recientes datos de Albert Carreras y y Manuel Jesús González sobre inversión pública y privada se deduce que la primera aumentó en un 57 por 100 entre 1945 y 1958, mientras que la segunda lo hizo, en el mismo período, en un 250 por 100 , y, asimismo, los da- 
tos disponibles entre 1958 y 1963 muestran una pendiente más acusada de crecimiento para la inversión privada que para la pública.

De todos modos, hay que notar que, como ya advirtieron Enrique FuentesQuintana y otros autores, el proceso liberalizador de la economía española, comenzado en 1959, no tuvo un desenlace coherente con.los principios teóricos en que se basaba ese cambio fundamental de política económica. Es cierto que la economía, en su apertura al exterior, experimentó un avance irreversible, como también lo es que se acentuaron los criterios de racionalidad económica y de sujeción a las reglas de mercado por parte de las empresas españolas. Pero no se acabó con el intervencionismo del Estado en la actividad económica -en amplios e importantes sectores, desde el financiero y la agricultura a la industria pesada-, ni el desarrollismo, como estrategia política explícitamente elegida, dejó de interferir en los procesos de inversión y de asignación de recursos. En parte esto ocurría porque en otros países europeos, tras la segunda guerra mundial, el sector público había adquirido un protagonismo mucho mayor que antes en las economías de mercado; lo justificaban la necesidad de nuevas y crecientes prestaciones sociales, la ideología socialdemócrata presente en todos los sistemas políticos occidentales, la actuación subsidiaria del Estado en la reconstrucción postbélica y la propia teoría económica vigente en los años cincuenta y sesenta, de raiz keynesiana. Pero en la España de ese tiempo, además, el Gobierno sentía la necesidad de recordar constantemente que el crecimiento económico, en parte, era posible $-\mathrm{y}$ en una parte nada desdeñable - por el modo en que el poder político conducía a la sociedad. Si había orden público, paz social, buenas relaciones con el exterior y aumento sustancial de la renta per capita, ello era posible, según el Gobierno, por la eficaz política del régimen, que se había adaptado a las nuevas circunstancias históricas. Naturalmente, para poder sostener esta imagen pública no se podía dejar de reclamar una presencia destacada del Estado, a menudo con marcados desvíos de los criterios de rentabilidad social, en la inversión industrial - y no sólo en la pública, sino también en la privada, por medio de subsidios, exenciones y créditos privilegiados-, en el desarrollo regional, en el estímulo a la exportación, en la regulación de cultivos y cosechas y en las propias organizaciones representativas de los intereses de empresarios y trabajadores.

Entre 1960 y 1975, la prosperidad económica fue el gran argumento justificativo del régimen, $y$, sin embargo, en sus años finales, la gran masa de españoles, ajenos hacía muchas décadas a las cuestiones políticas, y cuyo bienestar material había aumentado a la par que su insensibilidad ideológica, comenzó a inquietarse cada vez más ante fenómenos para ellos muchas veces inexplicables o atribuibles a causas ajenas a su propio mundo. En el capítulo 7 de su ensayo sobre Franco, Juan Pablo Fusi recoge algunos de estos hechos 
alarmantes para la mayoría del país: el aumento de huelgas y conflictos sociales a partir de 1970 - con consecuencias terribles, como las muertes de trabajadores-, el recrudecimiento de las protestas de los universitarios, en actitud cada vez más radical, y, sobre todo, los problemas, progresivamente agravados, del País Vasco, cuya culminación fue la secuencia que va desde el proceso de Burgos, en 1970, a los fulminantes procesos y ejecuciones de acusados de pertenecer a organizaciones terroristas en 1975, poco antes de morir Franco, mediando, entre tanto, la conmoción nacional que supuso el asesinato del almirante Carrero Blanco.

La muerte de Carrero era, además, un símbolo de la debilidad política - no visible para muchos- del régimen de Franco. En 1965 había desaparecido casi todo vestigio de entusiasmo popular hacia los ideales originarios del franquismo, como la Falange o el nacionalismo católico. De la misma manera que la política económica de la autarquía había caído en un desprestigio generalizado, los viejos símbolos del Movimiento quedaron arrumbados de la sociedad española, quince años antes de desaparecer Franco. Después de 1960 fue estadísticamente muy raro, casi imposible, encontrar universitarios que eligieran participar en la actividad política del régimen. Lo mismo cabría decir en la década de 1960 de otros sectores de la juventud española, desde los trabajadores industriales a los campesinos. Incluso las organizaciones oficiales de la juventud con fines recreativos y deportivos hubieron de relegar y omitir sus ritos y signos de origen falangista. Por ello, como bien explica Fusi, la tendencia del sector del régimen franquista que encabezaban Carrero y López Rodó, ya en los últimos diez an̂̉os del franquismo, se basaba en un proyecto político alejado, al menos en lo exterior, de lo que pudiera recordar los orígenes fascistas del autoritarismo español: un gobierno fuerte, con cuatro objetivos claves: $1^{\circ}$ ) terminación del proceso institucional abierto por la Ley Orgánica del Estado en 1966, que posiblemente fue aprobada con la mayoría real de los votos populares, aunque no en las proporciones que la propaganda luego pretendió; 2..$^{\circ}$ desarrollo económico, como fórmula disuasoria de cualquier deseo de cambio político que implicara riesgo para el bienestar de la mayoría de los españoles; $3^{\circ}$ ) reforma administrativa descentralizadora, y 4. $\left.{ }^{\circ}\right)$ Monarquía continuista personificada en don Juan Carlos de Borbón.

Se trataba de sistematizar un modelo político definitivamente desembarazado de los residuos totalitarios de la guerra, pero que no acababa de aproximarse a las democracias occidentales. Probablemente - no sería éste el caso del almirante Carrero- había entre sus valedores quienes opinaban que era mejor encauzar tímidamente el aparato institucional y administrativo en un sentido aperturista, confiando en que una combinación de desarrollo económico y de relaciones cada vez más estrechas con el exterior, junto al inexorable 
paso del tiempo, acabarían, a medio o largo plazo, introduciendo a España sin traumas en el conjunto político europeo.

El proyecto político de los falangistas, alternativo al anterior, era aún más exótico para un país de Europa occidental, aunque, según Fusi, tenía algunos antecedentes históricos reales en el mundo hispánico, como el PRI mexicano: se trataría de convertir, sin demasiadas complicaciones de orden práctico, al profuso y difuso aparato del Movimiento en una organización rectora de la vida política, donde las restantes fuerzas - no todas, por supuesto- acabaran siendo legalizadas, aunque sin alcanzar más que una actuación secundaria. A estas alturas resulta difícil saber cuál de estos dos proyectos tenía en la realidad más posibilidades de supervivencia; probablemente, ninguna en ninguno de los dos casos. De hecho, las formas externas institucionales, pálidamente recordatorias del conservadurismo europeo, que los carreristas pretendían preservar, se vieron enfrentadas brutalmente a la necesidad que manifestaba el autoritarismo de defender, incluso con el uso de la fuerza, su principio definitorio: la razón en virtud del poder. En la escalada de conflictos sociales que tuvo lugar entre 1965 y 1975 , el proyecto carrerista fue mostrando cada vez con más claridad su incoherencia e inviabilidad, hasta que el atentado contra el almirante cerró, con la más expresiva y cruenta de las imágenes posibles, el intento de su aplicación a la sociedad española. Al régimen de Franco sólo le restaba una última y confusa etapa, con un jefe de Gobierno que era, según Juan Pablo Fusi, a la España de entonces lo mismo que Calomarde, el ministro reaccionario de Fernando VII, fue a la España de la encrucijada entre absolutismo y liberalismo. Pero, además, desde el punto de vista estrictamente económico, la muerte de Carrero vino a coincidir con una crisis económica internacional que, desencadenada por el súbito encarecimiento de la energía, acabó cuestionando las rigideces institucionales del Estado de bienestar en todos los países occidentales. La crisis obligó a severos reajustes en la política fiscal y monetaria, y provocó una oleada de sustitución de industrias poco rentables por otras tecnológicamente más avanzadas. Algunos especialistas, como José Luis García Delgado y Julio Segura, han dedicado varios trabajos a estudiar este último capítulo de historia económica del franquismo, en que el estancamiento comenzó a mostrar una imagen bien distinta del desarrollo sostenido que había experimentado la sociedad española en los últimos quince años. Esas circunstancias, con las inevitables consecuencias sociales de inflación y paro, fueron tan determinantes, probablemente, como el magnicidio de Carrero Blanco y la propia muerte de Franco en la desorientación que mostraba el Gobierno de Arias Navarro a la hora de elegir una estrategia política, y contribuyen a explicar la relativa facilidad con que se desmontaron los mecanismos del viejo régimen.

Uno de los rasgos más notables de la historia del franquismo, incluyendo 
en ella la evolución económica del período, es el distanciamiento cada vez mayor entre la modernización y el crecimiento económico, por un lado, y la peculiar evolución política del país $\longrightarrow$, mejor dicho, la imposibilidad de su evolución política-, por otro. Juan Pablo Fusi subraya el carácter personalista del régimen franquista como una de las razones más obvias de su incapacidad para adaptarse a los tiempos. Sobre todo si se tiene en cuenta que la sociedad española estaba cambiando sus modos de comportamiento personal y comunitario, y sus normas de general aceptación, de acuerdo con el proceso de crecimiento económico. Un espectador de la sociedad española de 1970 podía advertir, junto a un grado sobresaliente de transformación económica y social, cómo se daban también cambios acusados en la localización urbana de la población española, en la incorporación cada vez mayor de la mujer al mundo laboral, en la comunicación creciente entre los españoles y el resto de los europeos occidentales, sobre todo los jóvenes, y, a la vez, en la homogeneización progresiva de las preferencias culturales y de los criterios de valor de aquéllos con éstos. En la historia económica de la España reciente, si bien resulta imposible la verificación de algunas predicciones marxistas (como la pauperización creciente de las clases trabajadoras o el aumento del control de la actividad económica por parte de unos pocos monopolistas), sí resulta, en cambio, fructífero aplicar otras deducciones del materialismo histórico, como la adecuación cultural de la sociedad a su organización económica y la presión que de ello se deriva sobre sus instituciones políticas. En este sentido, el libro de Juan Pablo Fusi proporciona una apasionante visión general de cuarenta años de vida española, en los que su principal protagonista aparece proyectado sobre un complejo panorama de alteraciones políticas internacionales, cambios económicos y modificaciones profundas de la sociedad y de la cultura españolas. 